\title{
Holistic care should be coming your way
}

\author{
N. Wilson ${ }^{1}$
}

In brief

Suggests there is a pressing need to translate the importance of oral health to general health and

wellbeing into general healthcare provision.
Suggests that integrating oral healthcare into general healthcare provision will create important opportunities for the dental team.
Highlights that new approaches to dental education, training and workforce planning are required to support much-needed developments in holistic healthcare provision.

In this Opinion article, Nairn Wilson argues that interprofessional, holistic healthcare provision greatly enhances general health and wellbeing. For dentistry-oral healthcare provision to realise its potential in whole patient care, it must be integral to developments in holistic healthcare provision.

If you or a member of your family has, or develops a chronic non-communicable disease, or a life-threatening illness, would you wish the responsible healthcare providers to take a whole person approach, including consideration of personal attitudes and values, in determining the most suitable care plan? If so, you should be supporting, if not lobbying for accelerated moves to interprofessional education and collaboration in healthcare sciences, and new, much-needed momentum in shifting to holistic healthcare. ${ }^{1}$ Dentistry must be involved in such initiatives, given the ever-growing body of evidence of associations between poor oral health and systemic and other conditions. ${ }^{2}$

Why do dentistry and oral health provision continue to be poor relatives in general healthcare and wellbeing considerations? Is it a result of ingrained perceptions among medical colleagues, ${ }^{3}$ especially those who determine healthcare policy, inadequate future proofing of educational guidance for programmes of dental studies, ${ }^{4}$ or a failure of the dental profession to press for arrangements which will allow dentistry to realise its potential in forward looking, value-based, preventatively-orientated,

Emeritus Professor of Dentistry, King's College London Dental Institute

Correspondence to: Nairn Wilson

Email: nairn.wilson@btinternet.com

Refereed Paper. Accepted 24 August 2017

DOI: 10.1038/sj.bdj.2017.878 minimal intervention, patient-centred care? A further possible cause is money, given that new funding would be required to get dentistry from where it is presently to where it should be positioned in the big healthcare picture, with the prospects of substantial medium to long-term efficiency savings. Sadly, it is suggested that oral healthcare remains largely contained in a 'dental silo' for all these reasons, to a greater or lesser extent - a Gordian knot, or a golden opportunity for a high-level, innovative change of direction in the best interests of patients. Everything points to a golden opportunity, with good prospects of future cost-containment and associated knock on benefits; for example, retention of the exceptional talent which continues to be attracted to a career in dentistry.

If you are not yet convinced of the need to sign up to interprofessional, holistic healthcare, with dentistry in the thick of the arrangements, then consider the challenges of 'teeth for life' and the provision of lifelong oral healthcare. As concluded at a United Nations 'high-level' meeting, ${ }^{5}$ to address these challenges, oral healthcare (dentistry) must be integrated into a 'healthy-life approach', requiring a transformation of health systems, coordinated at different levels of government and regulation. ${ }^{6}$ While the way forward is clear, some would say incontrovertible, and it is widely accepted that failure to take early action of the type suggested in the face of growth in high-health-cost elderly populations will severely stress already hard-pressed health systems, there would appear to be a lot of heads in the sand, or people with their hands tied, real or perceived, for one reason or another. Time to face up to the need for action, difficult as it may be, and for those with the power and authority to act or be given a mandate to effect transformational change.

For any remaining 'doubting Thomas', how will dentistry, unless engaged in transformational change, relate to medicine of the future, and if left behind, what will the future hold for dentistry? Medicine is anticipated to be transformed by ground-breaking innovations in healthcare and related pharmaceutical sciences, which are being realised at an everincreasing rate. ${ }^{7}$ In a similar way to colleagues in medicine and other healthcare professions tending to have limited knowledge of certain oral and dental matters, ${ }^{8}$ dentistry could find itself struggling to understand details and the significance of aspects of general healthcare provision of the future. Such disconnects are not in the best interests of patients, let alone healthcare professions. Whenever and wherever these disconnects exist, or may be anticipated, action should be taken to overlap and blur healthcare interfaces.

As and when holistic care becomes the norm, what arrangements may exist for its delivery in the primary care sector? General dental practices would be best embedded and fully integrated into holistic care health centres, with opportunity to work collaboratively with all other health and social care professions, including, among others, general medical 
practitioners, paramedics, general practice nurses, community nurses and social care practitioners, occupational and mental health therapists and all members of the pharmacy team. ${ }^{9}$ Contractual and funding provisions for such arrangements would be far removed from existing arrangements for primary care dentistry, ideally with members of the dental team having terms and conditions equivalent to their medical counterparts. In secondary care, dental teams would work much more closely than at present with, for example, diabetology teams and those providing care for the elderly, wherever possible in community settings, blurring the boundaries between primary and secondary care. Across the spectrum of clinical practice, the focus would be preventatively orientated, patient-empowering, longitudinal holistic care. This approach embraces many of the recommendations of the Steele report, ${ }^{10}$ but in the context of a whole-person, integrated approach to maintaining oral health, as an integral element of maintaining general health and wellbeing. Further goals in developing such arrangements would be reductions in health inequalities, deploying resources and service provision in communities with recalcitrant, high levels of oral and dental disease, and full involvement in the digitisation of healthcare to encourage and promote e-health.

To realise such goals, general dental practitioners (GDPs) would, it is suggested, require postgraduate training comparable to that provided for general medical practitioners to become expert generalists, with opportunity to develop a special interest and build expertise in areas most relevant to their clinical practice. This might be in the care of children, older patients with multi-morbidities, or individuals with chronic non-communicable diseases. Alternatively, the special interest and expertise may be in leadership, information technologies or practice-based research. Whatever career pathway chosen, the GDP of the future would have a greatly enhanced, dynamic role to play in general healthcare provision - as much, if not more a physician than a surgeon in contributing to the longitudinal care of patients and families.

Given anticipated future pressures on the national healthcare system, it is considered inevitable, sooner or later, that any oral healthcare provision beyond a core service, especially the provision of non-essential, sophisticated and appearance enhancing forms of care will be delivered under private contract. The private market in dentistry, including insurance-based oral healthcare provision is therefore set to continue to increase, possibly changing the nature of the business of dentistry, and the support that practitioners need and expect from professional bodies.

Patients finding it difficult to access, or opting out of state funded (NHS) routine dental care, may have the opportunity to have their oral healthcare requirements provided as part of a 'total health' package, offering preventatively orientated general health and wellbeing maintenance programmes. Such services, in common with NHS services, would require specialist practitioner support for the provision of certain forms of advanced care. How many specialists would be required in each of the distinct branches of dentistry, and the future composition of the dental workforce to meet all the needs and expectations of the growing, increasingly diverse population, would need to be the subject of sophisticated, longitudinal workforce planning. Such planning would be complicated by evolving roles and responsibilities and future levels of education and training of the different members of the dental team - a dynamic skills matrix, but one in which the dental practitioner must remain the leader of the dental team.

Is all this a threat or an opportunity? It is certainly a threat to dentistry as we know it today, especially traditional, reactive, mechanistic, 'drill and fill' dentistry, which must increasingly be seen to be outmoded. For young and future members of the dental profession, it should be seen to be a great opportunity. However, the future for each generation is what they make it, and getting from where dentistry is today to where it should be will be difficult, especially if there is lack of engagement and key stakeholders do not work together. New generation leaders with vision, conviction and commitment are required to drive what could become a very exciting agenda. So, the challenge to young and future members of the profession is: ask not what holistic care can do for you, ask what you can do to secure a future in the provision of holistic care.

I for one look forward to whatever dental care I may require in years to come being provided as an integral element of holistic, total-patient care, aimed at optimising my general health and wellbeing. I suspect that I am not alone.

For those interested in holistic dentistry, a conference on the topic will be held at the National Motorcycle Museum in Solihull, UK on Friday 3 November 2017, hosted by the FGDP(UK) in partnership with Simplyhealth Professionals.

1. National Collaboration for Integrated Care and Support. Integrated care and support: our shared commitment. 2013. Available at https://www.gov.uk/government/ uploads/system/uploads/attachment_data/file/198748/ DEFINITIVE_FINAL_VERSION_Integrated_Care_and_ Support_-_Our_Shared_Commitment_2013-05-13.pdf (accessed September 2017).

2. Chapple I L C, Wilson N H F. Manifesto for a paradigm shift: periodontal health for a better life. Br Dent $J$ 2014; 216: 159-162.

3. National Institute of Dental and Craniofacial Research. A national call to action to promote oral health. 2003. Available at https://www.nidcr.nih.gov/DataStatistics/ SurgeonGeneral/NationalCalltoAction/nationalcalltoaction.htm (accessed September 2017).

4. Wilson N H F. Future-proofing educational guidance. $\mathrm{Br}$ Dent J 2016; 221: 209.

5. Benzian H, Bergman M, Cohen L. The UN high-level meeting on prevention and control of non-communicable diseases and its significance for oral health worldwide. J Pub Health 2012; 72: 91-93.

6. ASTM International. Standard practice for managing sustainability in dentistry. 2015.

7. The King's Fund. Medical advances: Future trends. Available at https://www.kingsfund.org.uk/projects/timethink-differently/trends-medical-advances (accessed September 2017).

8. Renton T, Wilson N H F. Understanding and managing dental and orofacial pain in general Practice. Br J Gen Pract 2016; 66: 236-237.

9. Wilson N H F, Soni A. Interprofessional working: a spearhead opportunity for dentistry and pharmacy. Br Dent J 2016; 221: 607-608.

10. NHS England. NHS dental services in England. 2009. Available at http://dorsetldc.org/pdf/Independent $\% 20$ Review\%20of\%20NHS\%20Dentistry_Full\%20Report. pdf (accessed September 2017). 